DOI: $10.5433 / 1679-4842.2020 v 23 n 2 p 300$

\title{
Contribuições da Ontologia do ser social para uma concepção dialética acerca da relação teoria e prática no Serviço Social brasileiro
}

\author{
Contributions of the social being ontology to a dialectical conception about the theory and \\ practice relation in the Brazilian Social Work
}

\author{
Liliane Santos Tobias* \\ Jamerson Murillo Anunciação de Souza**
}

\begin{abstract}
Resumo
O artigo analisa a influência da Ontologia do ser social, obra máxima do filósofo Gyorgy Lukács, em textos clássicos da tradição teórica do Serviço Social brasileiro. O eixo de análise é a relação teoriaprática, com enfoque sobre suas especificidades e unidade ontológicas. A hipótese de trabalho perseguida na exposição é a ideia de que a tradição marxista, adensada pela "perspectiva ontológica" lukacsiana, ensejou aprofundamentos teóricos necessários ao avanço da reflexão crítica sobre a sua natureza e o significado social do Serviço Social na reprodução das relações sociais. A perspectiva teórica que orienta a investigação e a exposição é o materialismo histórico. A metodologia é a pesquisa bibliográfica, com abordagem qualitativa.
\end{abstract}

Palavras-Chaves: Ontologia. Teoria-prática. Ideologia. Cotidiano.

\begin{abstract}
The article analyzes the influence of the Ontology of the Social Being, the maximum work of the philosopher Gyorgy Lukács, in classical texts of the theoretical tradition of the brazilian Social Work. The axis of analysis is the theory-practice relationship, focusing on its specificities and ontological unity. The hypothesis of work pursued in the exhibition is the idea that the marxist tradition, thickened by the Lukacsian "ontological perspective", gave rise to the necessary theoretical deepening to advance the critical reflection on its nature and the social meaning of Social Work in the reproduction of social relations. The theoretical perspective that guides research and exposition is historical materialism. The methodology is bibliographic research, with qualitative approach.
\end{abstract}

Keywords: Ontology. Theory-practice. Ideology. Daily.

\footnotetext{
* Assistente Social e Mestre em Serviço Social pela Universidade Estadual da Paraíba.

** Assistente Social, Mestre e Doutor em Serviço Social pela Universidade Federal de Pernambuco. Professor do Departamento de Serviço Social da Universidade Federal da Paraíba
} 


\section{Introdução}

A relação entre teoria e prática é uma questão importante para o Serviço Social no Brasil. Essa importância se expressa nas dimensões da produção de conhecimento, do exercício profissional, e da formação acadêmica, na medida em que confere conteúdo histórico à pesquisa, sentido intelectivo e operativo à prática, e densidade ético-política no processo formativo de gerações de assistentes sociais. Vinculada a diferentes matrizes de pensamento social e filosófico, entretanto, essa relação pode ser concebida de formas antagônicas: numa chave dicotômica, idealista, que separa os termos como dimensões isoladas, como no positivismo e no conservadorismo; ou em um prisma de unidade dialética e materialista, que considera as especificidades de ambas, reconhece a prioridade da prática e o caráter de reprodução intelectual da teoria social para o marxismo; para citar apenas dois exemplos.

A concepção conservadora, positivista, é predominante na sociedade capitalista, e serve como lógica estruturante da institucionalidade pública e privada. Por motivo de espaço e de escopo, não é possível avançar sobre esta particularidade. Nosso enfoque recai sobre a perspectiva dialética, especificamente a partir das contribuições do pensamento maduro de Gyorgy Lukács (2013), condensado na obra Para uma ontologia do ser social II, entendido neste trabalho como "perspectiva ontológica". E com o objetivo de perseguir nossa hipótese de trabalho, que aponta para a específica contribuição dessa perspectiva ao amadurecimento da reflexão crítica sobre o significado social da profissão de Serviço Social, recuperaremos três obras nas quais se expressa a tradição marxista, buscando nelas a específica influência da "perspectiva ontológica", identificada por meio do uso de categorias teóricas e reflexões analíticas extraídas e inspiradas do pensamento lukacsiano maduro. Escapa aos nossos objetivos a recuperação das polêmicas envolvendo o pensamento do último Lukács no interior da tradição marxista.

As obras, escolhidas por sua relevância e originalidade no debate intelectual, são: Capitalismo Monopolista e Serviço Social de José Paulo Netto (2011), A instrumentalidade do Serviço Social, de Yolanda Guerra (2009) e Ética: fundamentos sócio-históricos, de Maria Lucia Barroco (2010). Tomadas como unidade, elas estabelecem uma crítica materialista e dialética à chave positivista sobre a relação teoria e prática; tomadas como particularidades, cada uma avança reflexões específicas sobre as dimensões teórico-metodológica, ético-política e técnico-operativa, sem prejuízo da matriz comum: a perspectiva ontológica. 
Para concretizar uma abordagem dessa natureza, a pesquisa bibliográfica se impõe como metodologia que melhor se alinha aos objetivos desta exposição, pois além de permitir assentar os pressupostos teóricos da perspectiva ontológica como pontos de partida da análise, enseja a leitura comparativa das obras selecionadas, constituídas, assim, como objeto de estudo.

\section{A Tese do Sincretismo e sua Influência Lukacsiana}

A obra Capitalismo monopolista e Serviço Social foi publicada pela primeira vez em 1992. Seu objetivo, segundo o autor, era fornecer um quadro da constituição do Serviço Social até a década de 1960, identificando os substratos ídeo-culturais que conformavam a profissão, em seus aspectos teórico-práticos, antes do processo de renovação.

A primeira parte desta obra, contempla a gênese histórica do Serviço Social como profissão e a segunda a sua compreensão como sistema sincrético. Nesta, o autor identifica as contradições entre teoria e prática que fundamentam a profissão e as especificidades da estrutura sincrética no âmbito da prática, da ideologia e do pensamento científico. Além disso, deixa clara a necessidade de analisar articuladamente estas estruturas que, na sua visão, compõem o arcabouço sincrético que envolve a profissão e se constitui desde a sua gênese.

O processo de institucionalização imputou a necessidade da adoção de recursos teóricos para sistematização da prática profissional, aproximando a profissão dos conhecimentos advindos das Ciências Sociais. Esta aproximação, contudo, atribuía os aportes "científicos", que lhe serviram de base de legitimação, como fundantes da profissão, como forma de se contrapor ao perfil profissional de suas protoformas, baseando na ciência (hipostasiada) o estatuto profissional. De acordo com Netto, este entendimento desconsidera a configuração real a partir das demandas histórico-sociais macroscópicas: “[...] não se constata apenas a inversão que tem sido própria do Serviço Social - buscar a gênese de suas redefinições profissionais na alteração do sistema de saber que o referencia, típica operação de (auto)ilusionismo ideológico." (NETTO, 2011, p. 90). Para o autor:

O sincretismo nos parece ser o fio condutor da afirmação e do desenvolvimento do Serviço Social como profissão seu núcleo organizativo e sua norma de atuação. Expressa-se em todas as manifestações da prática profissional e revela-se em todas as intervenções do agente profissional como tal. O sincretismo foi um princípio constitutivo do Serviço Social (NETTO, 2011, p. 92, grifo do autor).

Ao identificar a funcionalidade da intervenção profissional na relação estabelecida com as classes antagônicas (a "questão social" como eixo original das demandas profissionais 
e a sua relação com as políticas sociais e com o Estado burguês), considera que o traço sincrético é constitutivo do Serviço Social, no quadro da sociabilidade capitalista monopólica.

É possível perceber nesta análise, a mediação direta entre as categorias ontológicas lukacsianas e as questões teórico-culturais do Serviço Social, no tocante as concepções de causalidade, totalidade e ideologia; remetendo à gênese da profissão localizada nos complexos categoriais presentes na realidade brasileira no contexto da profissionalização, apreendendo-os na totalidade e historicidade com que se expressam. Outro elemento extraído da ontologia do ser social que podemos identificar na elaboração de Netto, é o cotidiano: horizonte real que baliza a intervenção profissional.

Não está em tela, nesta determinação, a referencialidade compulsória de todas as objetivações sócio humanas a vida cotidiana [...]; o cotidiano como horizonte real da intervenção profissional do Serviço Social denota, antes, que ela transita necessariamente pelos condutos da cotidianidade: seu material institucional é a heterogeneidade ontológica do cotidiano [...] e seu encaminhamento técnico e ideológico [...] não favorece "suspensões" ou operações de "homogeneização" (NETTO, 2011, p. 95-96).

A dimensão do cotidiano é, pois, um complexo permeado por contradições, pela imediaticidade e por determinações ideológicas. Localiza assim a funcionalidade da profissão na organização dos componentes heterogêneos do cotidiano, ressituando-os através de uma manipulação planejada das refrações da "questão social" que requisitam a sua intervenção. (NETTO, 2011, p. 96). Na manipulação de variáveis empíricas do cotidiano - nos conhecimentos instrumentais e paradigmas explicativos que direcionam os processos sociais - e na reposição intelectual do sincretismo, estão dados os meios de análise formal-abstratas que legitimam o exercício manipulador (NETTO, 2011, p. 98-99).

No tocante as especificidades do sincretismo e a prática indiferenciada ${ }^{1}$, na estrutura sincrética no Serviço Social, o autor sinaliza que embora a profissionalização tenha instaurado um quadro ideal que cortou com as protoformas - ancorado em um sistema de saber e enquadrado em uma rede institucional - não redundou em diferenças significativas no âmbito da prática, permanecendo as intervenções de caráter assistencialistas: "[...] a profissionalização permanece um circuito ideal que não se traduz operacionalmente".

\footnotetext{
1 José Paulo Netto (2011) desenvolve a ideia de "prática indiferenciada" na seção 2.3 da obra Capitalismo Monopolista e Serviço Social, no contexto do processo de institucionalização e mudanças das bases ideológicas da profissão. Para o autor, a profissionalização alterou a inserção sócio-ocupacional e o significado social do trabalho do assistente social, entretanto, no âmbito da prática interventiva, naquele momento, estabeleceramse poucas mudanças em relação as práticas filantrópicas.
} 
(NETTO, 2011, p. 104). A resposta para esta dualidade presente na prática profissional, foi buscada por Netto nas concepções lukacsianas de irracionalismo, "destruição da razão" e na razão formal-abstrata que conduzem a capitulação em face aos problemas de fundo colocados pelo movimento do real (NETTO, 2011p. 100-101). Esta forma de racionalidade oferece:

[...] um arsenal de instrumentos de manipulação para o controle de níveis singulares da dinâmica social. Este repertório técnico tem a sua racionalidade hipotecada às regularidades sociais epidérmicas da ordem burguesa - ele é, essencialmente, a transcrição imediata destas ao plano do pensamento formal-abstrato (NETTO, 2011, p. 101).

Assim, na falta de um referencial crítico, a articulação teórico-prática busca fornecer uma explicação "coerente" que pode ser instrumentalizável ao nível de "eficácia” na prática, correspondente ao quadro geral da aparência dos fenômenos que se apresentam no momento da intervenção: "[....] este referencial não rompe com a positividade [...] porque não supera a sua imediaticidade." (NETTO, 2011, p. 101).

No tocante a concepção de ideologia, é possível identificar que advém do pensamento lukacsiano, como representação das ideias que se disseminaram e se tornaram aceitas por uma maioria, legitimando determinadas concepções de mundo, do momento sócio-histórico e econômico-político do qual se refere, buscando estes elementos para embasar o pensamento ídeo-cultural que se disseminou nas práticas profissionais e seus traços sincréticos, lastreados no pensamento conservador.

O pensamento científico, para Lukács, é uma forma de ideologia, pois contribui com a busca de respostas (instrumentalizáveis e direcionadas à resolutividade dos conflitos sociais), permeando a consciência dos sujeitos. Ao identificar o pensamento científico como parte da estrutura sincrética, Netto determina os elementos essenciais que são constitutivos para a relação estabelecida entre teoria e prática.

Quanto a concepção de "ciência", o autor faz uma exposição remetendo às características do seu ser em si, portanto, ontologicamente. Define ciência como uma categoria, basicamente pensada como ultrapassagem da "falsa consciência", que comporta simultaneamente uma vinculação de classe e um elemento de autonomia relativa e que é essencialmente concebida como uma arma crítica contra quaisquer representações apologéticas (NETTO, 2011, p. 134). Sinaliza as diferenças substanciais entre a concepção marxiana e a tradição positivista - onde indica uma "homogeneidade epistemológica entre conhecimento da sociedade e o da natureza." (NETTO, 2011) - e esboça a concepção da obra 
marxiana como sendo uma teoria social (e não ciência). Esta concepção é extraída por Netto do pensamento de Lukács.

\begin{abstract}
Entendemos que é mais correto, [...] abandonar a tradição marxista que caracteriza a obra marxiana como ciência social - tradição ela mesma contaminada pelos padrões positivistas e suas derivações. Preferimos pensar a obra de Marx como fundante de uma teoria social, que articula uma postura nitidamente ontológica [...] com uma radical historicidade: trata-se de uma teoria sistemática (não um sistema) que dá conta do movimento do ser social que se engendra na gênese, consolidação e desenvolvimento (aí incluídas as condições do seu perecimento) da sociedade burguesa (NETTO, 2011, p. 135).
\end{abstract}

Para o autor, a ultrapassagem desta positividade e a apreensão da racionalidade do processo real e da sua legalidade é dada, pela ontologia: “[...] teoria social que extraia do movimento do ser social [...] as suas determinações concretas [...] e que, portanto, não tenha um valor puramente instrumental" (NETTO, 2011, p. 135). Nesta concepção ontológica da teoria social, Netto traz para o Serviço Social os influxos do método crítico-dialético.

A localização do cariz receptador do Serviço Social dos saberes especializados advindos das ciências sociais e o desenvolvimento de um sistema de saber de segundo grau, "[...] obtido pela acumulação seletiva de subsídios das ciências sociais conforme as necessidades da própria profissão." (NETTO, 2011, p. 135, p. 146), são traços eminentemente sincréticos, que tem no ecletismo o seu ser constitutivo. Para o autor isto figura um caráter ativo da profissão, no que tange a busca de referenciais interpretativos, que sempre estiveram travejados pelo sincretismo ideológico conservador.

No processo de teorização é possível identificar a flagrante dicotomização entre teoria e prática, que tem raízes, nas peculiaridades de seu desenvolvimento ídeo-cultural e teórico-metodológico, na tentativa de filiação teórica com pertinência direta para a sua intervenção prática e a mescla de valores morais orientando as intervenções, portanto, permeadas pela racionalidade instrumental, com referenciais diversos que confluem ecleticamente no âmbito prático-operativo.

A análise sobre a prática indiferenciada, tornou-se centro de polêmicas, devido a incidência da sua proposta na natureza da profissão. Muitos destes argumentos têm como plano de fundo o fato de o autor ter justificado, como um dos elementos do traço sincrético no âmbito da prática, naquele momento, a falta de referencial crítico capaz de reverter as 
análises superficiais e a imediaticidade fenomênica da realidade, que se apresenta no cotidiano.

Em resolvendo a reificação, seria possível ao pesquisador entender as bases do sincretismo, entretanto este não cessaria, uma vez que é parte das contradições imanentes na realidade capitalista. Assim, o autor chama atenção para uma questão de fundo: a própria dinâmica complexa, múltipla e infindável das refrações societárias da "questão social" que repercutem na intervenção profissional, acabam requisitando modelos formal-abstratos de intervenção, repondo novas causalidades e dificultando a apreensão dos sistemas de mediações (NETTO, 2011, p. 95).

Há, portanto, um argumento de maior relevância, necessário para localizar o sincretismo como constitutivo da realidade sócio-histórica burguesa, tendo em vista que a própria "questão social" e a modalidade de intervenção sobre esta, tendo por substrato as políticas sociais do Estado burguês, configuram organicamente traços sincréticos. Isto posto, mesmo superando-se o ecletismo nas análises profissionais, ultrapassando-se do ponto de vista da reflexão teórica a fenomenalidade do cotidiano: "[...] se, de um lado, cogita-se um processo de superação do ecletismo teórico, por outro lado, do ponto de vista do exercício profissional, o sincretismo é um componente ineliminável, uma vez que se encontra "[...] conectado a instâncias e mediações que ultrapassam e circunscrevem a profissão." (SOUZA apud WELLEN, 2018, p. 131-132, grifo do autor). Portanto, ontologicamente, continuam sendo repostos os condicionantes sincréticos na profissão.

lamamoto (2014, p. 267) identifica que é na problemática da reificação que Netto considera o sincretismo como princípio constitutivo da natureza da profissão, e com isto, o autor parte da: "[...] aparência em que se manifesta sem antes decifrar o que se oculta por traz da forma reificada." Com isto critica a tese do sincretismo de se contentar com a aparência mistificadora em que se apresentam os processos sociais, restringindo o universo da análise às formas reificadas de manifestação dos processos sociais: "[...] ainda que esse procedimento possa prevalecer no universo profissional, denuncia a mistificação, mas não elucida a natureza sócio-histórica dessa especialização do trabalho para além do universo alienado, em que se realiza e se mostra encoberto o sincretismo." (IAMAMOTO, 2014, p. 267268).

Porém, é necessário enfatizar que o sincretismo não é um aspecto exclusivo do modo de ser do Serviço Social. Netto localiza a natureza sócio-histórica dos traços sincréticos, que 
perpassam as demandas do cotidiano considerando a particularidade de inserção profissional e a multiplicidade de refrações do seu eixo central de atuação, a "questão social". Também problematiza o âmbito das respostas profissionais mediatizadas pelas políticas sociais focalizadas e fragmentadas - que imputam a recorrência a formas de racionalidades formalabstratas na intervenção profissional. Considerando estes aspectos, independentemente da "suspensão do cotidiano" que o profissional possa direcionar, sempre acabará tendo que, em algum momento, dar respostas a determinadas situações de forma imediata, pois não há como romper o sincretismo que constitui o modo de ser da ideologia burguesa.

Portanto, a nosso ver, Netto não coloca em xeque a capacidade crítica dos profissionais, nem a sua "relativa autonomia" em reconstruir as demandas de forma política, muito menos desconhece as formas de reificação - inclusive por entendê-las ontologicamente, identifica-as na totalidade, para além da profissão.

De acordo com o Netto, nesse contexto sincrético, a práxis é reduzida a burocratização da vida humana, perde a sua dimensão ontológica de atividade transformadora do real, para meramente reproduzir instrumentalmente a realidade. Nega-se a historicidade, as múltiplas determinações que compõe o objeto, a essência, a totalidade, as mediações que permeiam o conhecimento da realidade, para se ater aos "dados", as vivências imediatas, ao aparente.

Embora tenhamos aprofundado o adensamento crítico, que contribui com a ampliação dos horizontes analíticos, e acumulado uma reserva teórica considerável no esforço em superar o ecletismo, a permanência do referencial de extração positivista permanece no âmbito da prática profissional, dado o horizonte institucional de alocação dos assistentes sociais, dinâmica esta que repõe os fundamentos do sincretismo.

Entendemos que a tese do sincretismo é a expressão/manifestação dos componentes centrais do desenvolvimento teórico-prático do Serviço Social. Por esse motivo, ela demanda aprofundamentos e debates renovados. Os traços sincréticos apontados pelo autor, permitem identificar, ontologicamente, a problemática central da relação estabelecida entre teoria e prática na profissão, no que tange a mediação existente entre o seu sistema de saber, de representações ideais e as implicações no âmbito da intervenção prática na realidade, imersa na dinâmica contraditória da fenomenalidade da sociedade capitalista.

Considerando as categorias apresentadas no decorrer desta tese, percebemos que a sua exposição é de caráter genuinamente ontológico. Não apenas apresenta as categorias 
extraídas da ontologia do ser social, mas as articula ao desenvolvimento da profissão esboçando questões medulares e considerando a totalidade das dimensões que a compõe.

\section{A tese da instrumentalidade como desdobramento da perspectiva ontológica}

O texto de Yolanda Guerra é uma das elaborações clássicas do Serviço Social da década de 1990. Esta obra se atém a especificidade da instrumentalidade do Serviço Social para além da sua dimensão técnico-operativa. Traz a análise de que o conhecimento dos instrumentos e técnicas por si só, não são a prática do assistente social. Há uma instrumentalidade que perpassa todo o processo de desenvolvimento das mediações necessárias para a intervenção profissional, pautados em uma racionalidade reproduzida nas ações dos assistentes sociais, que se expressa nas suas representações ideais e no conjunto de valores apropriados pelos profissionais, que repercutem nas intervenções. Assim, a razão torna-se uma questão central da sua investigação.

A autora vai buscando desmistificar desde a configuração da razão moderna, até as implicações da racionalidade formal-abstrata requisitada pelo desenvolvimento capitalista, e, de como isto impacta o âmbito ideológico e as representações profissionais, aspectos que contribuíram significativamente com a centralidade do debate sobre a relação teoria-prática na profissão².

Guerra entende o recurso metodológico não como um conjunto de instrumentais que serão aplicados na realidade para manipulá-la, mas como uma síntese entre teoria, prática e método, dentro de uma processualidade histórica (construída no movimento do ser) e suas determinações dialéticas, a luz da teoria social crítica. A teoria é a reprodução ideal do movimento real do objeto, este é sempre mais rico e dinâmico que a consciência pode apreender, portanto, sinaliza que o método não soluciona as questões que apreende, apenas direciona para o seu conhecimento profundo.

Partindo deste pressuposto, elenca como "categoria de análise" a intervenção (a "dimensão mais desenvolvida" da profissão) como central para entender as suas

\footnotetext{
2 Cabe ressaltar que não existe possibilidade de vida sem a razão instrumental. Esta é necessária para pôr em movimento as condições materiais que permitem a transformação dos objetos concretos, portanto, é necessária para a manutenção da vida. Entretanto, apresenta um caráter imediatista, que tende ao processo manipulatório e alienador, assim, não permite uma complexidade do pensamento a partir da totalidade. $\mathrm{O}$ seu superdimensionamento gera implicações para o processo de conhecimento e para as possibilidades de superação da realidade aparente.
} 
possibilidades analíticas nos planos ontológico e lógico: “A análise da intervenção profissional no plano lógico nos possibilita apreender os diferentes graus e níveis da razão acionados nesse processo e, por isso, é capaz de indicar padrões de racionalidade que a sustentam." (GUERRA, 2009, p. 34).

A razão ganha centralidade na discussão trazida por Guerra, tendo por função “A reflexão que busca extrair dos processos sociais suas determinações concretas, seu caráter ontológico [pois] os processos sociais possuem uma racionalidade objetiva", assim, "[...] torna-se possível à razão apreender tanto a sua legalidade tendencial quanto as suas possibilidades internas." (GUERRA, 2009, p. 32). É a razão que possibilita a reconstrução dos processos sociais e, diante disto, a autora se detém a gênese das diversas racionalidades do Serviço Social em sua razão de ser e na sua razão de conhecer.

Com o objetivo de desvendar as racionalidades presentes no exercício profissional, caracteriza a sua concepção acerca de razão, indo aos clássicos das teorias modernas, com ênfase para a constituição da racionalidade formal-abstrata, sob crítica referendada pela racionalidade ontológica do ser social.

Para Guerra, há no Serviço Social a predominância do "paradigma" da racionalidadeformal-abstrata: analisada como produto do desenvolvimento capitalista, dado o caráter reificado das relações de produção, cuja direção está em escamotear a organização estrutural do sistema. Os modelos explicativos desta forma de racionalidade, encontram fundamentação na tradição positivista, reduz a razão a uma concepção instrumentalista, desconsidera os fundamentos que a determinam, se atendo apenas ao conhecimento que permita a sua manipulação, portanto, às necessidades imediatas.

A instrumentalidade do Serviço Social expressa uma racionalidade produzida tanto pelas ações dos profissionais, quanto nas suas representações. A divisão do trabalho material e intelectual tem por resultante que instrumentos e técnicas não sejam apenas apropriados como mediação à objetivação do ser social, mas se transformem em mediações reificadas. A requisição de modelos explicativos que sejam compatíveis com a aparência dos objetos de intervenção, direciona a busca de instrumentos e técnicas, que se "adequem" a realidade aparente.

A supervalorização dos instrumentos e técnicas na profissão, a ênfase na dimensão técnico-operativa em detrimento das suas outras dimensões, culmina na apropriação acrítica do conteúdo ideológico atribuído pela sociabilidade burguesa. Com a disseminação da 
racionalidade formal, positiva, para os demais âmbitos da totalidade dos processos sociais, o pensamento mantém-se irredutível em aceitar a unidade teoria-prática.

A resultante deste processo é o engendramento de representações fragmentadas, que delimitam duas formas de apreensão da profissão: ou como técnica ou tecnologia social ou como ciência ou área específica do saber. (GUERRA, 2009, p. 172). Para Guerra, há nestas duas direções equívocos substanciais, no que tange a compreensão da profissão desconectada da sua natureza constitutiva, enquanto profissão inserida na dinâmica de reprodução das relações sociais, requisitada socialmente para ocupar determinado espaço legitimado na divisão social do trabalho. É possível identificar então, a endogenia messiânica, com viés teoricista, que apontam para a dicotomização entre teoria e prática.

Isto posto, entendemos que as respostas das requisições instrumentais, não comportam o estabelecimento das alternativas e possibilidades de ação profissional, nem compõe a totalidade das dimensões que constituem a profissão, como sua capacidade analítico-ontológica e seu direcionamento ídeo-político, frente aos desafios postos pela ordem burguesa.

No final de sua construção teórica, Guerra trata das possibilidades políticas do Serviço Social, apropriando-se de categorias centrais do pensamento lukacsiano, refletindo sobre: "Causalidade e teleologia: o protagonismo dos sujeitos na direção teórica da sua práxis". Trata incialmente do processo de conhecimento, como direcionador da práxis do ser social, apreendido pela experiência e formulação de conceitos (a partir do desenvolvimento da linguagem e interação do ser social em seu processo de socialidade) conformando um quadro categorial representativo da realidade e viabilizador de transformações sobre estas.

Para a autora, as categorias ontológicas teleologia e causalidade, são fundamentais para a compreensão da teoria e da práxis. A capacidade teleológica dos sujeitos, contribui, pois, com o estabelecimento do caminho (projeções, finalidades, alternativas, possibilidades, etc.) que viabilizam a consciência tomar ciência das determinações da realidade e estabelecer os meios de ação, que só se materializará com a práxis, enquanto atividade transformadora da realidade.

Guerra deixa claro que as condições objetivas não dependem apenas da postura teleológica individual dos seus agentes e de seus instrumentos de intervenção, sendo necessárias mediações que permitam superar a dimensão fenomênica da racionalidade que se espraia na cotidianidade. Reconhece que há diversos elementos e condições adversas que 
obstaculizam o desenvolvimento crítico na prática profissional, que requerem muito mais que o conhecimento adequado de instrumentos e técnicas de intervenção, mas uma postura que não se contente com a aparência (nem a reproduza!) assumindo um caráter problematizador frente a fenomenalidade que se apresenta como demanda, na busca de estratégias que permitam a sua desmistificação.

A instrumentalidade do Serviço Social busca na fundamentação da perspectiva ontológica e suas categorias centrais, a reflexão crítica sobre a intervenção profissional e suas determinações, limites e possibilidades sócio-históricas, considerando a natureza da profissão e sua localização no âmbito interventivo. A problemática teoria e prática, compõe um dos eixos estruturantes da obra, superando o hiato que esta questão apresentava nos discursos e práticas profissionais.

No que tange a dicotomização entre teoria-prática, na instrumentalidade, a autora identifica que para uma profissão como o Serviço Social, a forma de conceber a práxis, como prática instrumental/procedimental, apenas como um conjunto de metodologias, um guia para a ação, retira da intervenção profissional qualquer pretensão analítica, ou seja, reproduzse imediatamente o cotidiano, para responder as demandas apresentadas, sem tecer nenhuma análise mais profunda do contexto social em que o profissional se insere. Limitandose as possibilidades de mediação teórica: fragmenta-se a articulação teoria-prática.

\begin{abstract}
A falta de uma reflexão ontológica e de uma perspectiva de totalidade na análise que permitam captar a funcionalidade da profissão às determinações do capitalismo [...] toma como novas, [...] aquelas atribuições e competências já reconhecidas como portadoras dos interesses de manutenção da "ordem e do progresso" do capitalismo: como uma receita nova para o velho pudim. Vistas como algo novo, essas práticas escondem as linhas que as vinculam àquelas que ora modernizavam, ora reatualizavam o histórico conservadorismo na profissão (GUERRA, 2004, p. 39).
\end{abstract}

Esta reatualização de posturas conservadoras, pode pôr em risco os avanços críticos e especialmente a direção estratégica ético-política. Nos termos da autora a profissão passa a ser vista como "ajuda psicossocial e/ou técnica de solução de problemas", operando uma "clara 'regressão idealista' na profissão." (GUERRA, 2004, p. 40). Do ponto de vista da prática reatualiza-se a tendência de compreender a questão social de um ponto de vista moral, no âmbito teórico-ideológico obstaculiza-se a análise do contexto mais amplo de onde se emanam as demandas.

Gostaríamos apenas de tratar de um elemento que identificamos como ontologicamente relevante e que, a nosso ver, foi pouco desenvolvido pela autora, dado o seu 
objeto de pesquisa, que é a dimensão do cotidiano. Este conceito aparece apenas na última parte de sua elaboração, onde a autora trata da cotidianidade definindo brevemente esta dimensão, e sugerindo aos leitores em uma nota de rodapé, o aprofundamento da "estrutura da vida cotidiana" na obra de Agnes Heller "O cotidiano e a história" e de Lukács "Introdução a uma Estética Marxista" (GUERRA, 2009, p. 180, nota de rodapé 132).

Para Lukács (2013), um aspecto necessário para a análise do ser social, é a vida cotidiana. Nesta se encontram elementos significativos para a reprodução da totalidade, uma vez que, a "concepção de mundo", como "imagem ideal e sentimental" da consciência dos homens, exerce grande influência sobre a sua reprodução. Comporta o caráter imediato, fenomênico, massivo da realidade, porém, é no cotidiano que "[...] as tendências para o serem-si, para a autoconsciência, via de regra, ganham validade" (LUKÁCS, 2013, p. 442), portanto, há que se considerar a importância desta esfera para o processo de conhecimento. Importa ressaltar que é no cotidiano que a relação entre teoria (como preparação consciente da práxis) e práxis possui a imediaticidade em sua máxima expressão: “Isso tem como consequência que, em todas as objetivações, o componente da alienação se reveste de uma importância maior do que de resto." (LUKÁCS, 2013, p. 449). Vejamos:

[...] na maioria dos casos de conflito, surge um deslocamento no âmbito da consciência, em que o homem, via de regra, considera como objetivamente existente aquilo que favorece o modo como ele conduz a sua vida, enquanto considera como objetivamente não existente aquilo que está em contradição com ela. [...] Em suas contradições, externa-se o caráter social desse desenvolvimento para a individualidade: a individualidade só conseguirá encontrar, em suas alienações, uma autoconfirmação, inclusive para si mesma e tanto mais para o seu ambiente, se elevar a autoafirmação contida nelas à condição de representante de uma camada da sociedade, de uma corrente social, acatada por ela. [...] Uma vez mais: não é como se por si mesmos pudessem criar um "mundo", mas é porque os homens, enquanto seres que respondem, posicionam-se em suas alienações diante das questões existenciais momentâneas da sua respectiva sociedade, decidindo mediante a afirmação ou a negação de alternativas em função das necessidades de sua própria personalidade (LUKÁCS, 2013, p. 449-450).

Neste fragmento, Lukács aponta para a repercussão e influência da "concepção de mundo" e das alienações para a consciência e a individualidade do sujeito. Demostra que a esfera do cotidiano, atua nas formas de representações fenomênicas que os sujeitos socialmente têm sobre o seu modo de vida e que autoconfirmam o contexto sociocultural que se inserem, buscando atender as suas próprias necessidades, legitimando determinadas alienações que representam a camada social da qual fazem parte. É o cotidiano o lócus privilegiado de disseminação das ideologias. 
Diante do exposto, por ser o cotidiano o espaço de reprodução imediata da consciência, onde se espraiam as ideologias, alienações e a racionalidade formal-abstrata, sentimos a falta de um desenvolvimento maior desta categoria, no entanto, entendemos que isto não prejudica a análise proposta pela autora, que sinalizou as suspensões desta cotidianidade como "matéria-prima" para as elaborações teóricas (GUERRA, 2009, p. 181) portanto, a ausência conceitual não retirou a importância do seu significado.

Como resultados essenciais de sua obra, Guerra nos atenta para a importância dos instrumentais técnicos, necessários na execução das atividades profissionais, estes são essenciais para um dado momento da intervenção profissional, no entanto, apenas os conhecimentos operativos, não refletem as possibilidades da prática de seus agentes. As intervenções cujo enfoque se estabelece apenas nas apropriações técnico-operativas, não comportam a totalidade das dimensões que constituem a profissão, como sua capacidade analítico-ontológica e seu direcionamento ídeo-político, frente aos desafios postos pela ordem burguesa.

É possível perceber também uma linha de continuidade com a discussão abordada por Netto, embora para a autora o processo de suspensão do cotidiano é capaz de romper com a fenomenalidade das demandas que imputam a intervenção profissional, não problematizando a reposição de novos fenômenos e uma continuidade de novas problematizações, que acabam por requisitar intervenções imediatas. Há que se considerar que o fortalecimento da mediação ontológica entre teoria e prática para a reconstrução crítica das demandas profissionais é, sem dúvidas, uma contribuição significativa desta tese para a tradição teórico-crítica do Serviço Social brasileiro.

\section{A reflexão ética sob inspiração lukacsiana na obra de Barroco}

O livro Ética: fundamentos sócio-históricos de Maria Lucia Barroco, publicado na primeira década de 2000, compõe a biblioteca básica do Serviço Social ${ }^{3}$ e se tornou uma referência no processo de formação profissional, em virtude do resgate da gênese da ética e

\footnotetext{
3 Coletânea que trata de conteúdos fundamentais que perpassam o Serviço Social sob responsabilidade da Cortez editora. Utilizamos este livro pois não dispomos da obra desenvolvida pela autora intitulada: "Ética e Serviço Social fundamentos ontológicos." Assim, justificamos que embora se trate de uma exposição mais didática, foi possível identificar a influência de Gyorgy Lukács, que nos permite avaliar a sua contribuição para o atual Código de Ética do Serviço Social brasileiro.
} 
sua especificidade no Serviço Social. Segundo a autora, o seu objetivo é ir além da aparência e chegar aos fundamentos da ética passando pelos fundamentos do ser social ${ }^{4}$.

Fundamenta-se na centralidade da categoria trabalho e sua importância para o processo de gênese e socialização do ser social; analisa o papel da consciência e subjetividade e da capacidade teleológica na projeção e pré-idealização das finalidades e dos meios para efetivação da práxis; aponta as alternativas e possibilidades de escolhas, que resultam nas concepções de valoração dos pores teleológicos e na gênese da liberdade; bem como tece considerações acerca da ideologia e da vida cotidiana.

Na cotidianidade, estão postas a imediaticidade, a reprodução das normas de comportamentos e costumes morais, direcionados a reprodução do indivíduo singular, aspectos que configuram uma singularidade alienada. Dada a possibilidade de discernir entre valores "[...] o indivíduo vincula-se a sociedade e reproduz o desenvolvimento humanogenérico, mas as formas desta incorporação caracterizam-se por uma dinâmica voltada à singularidade, não a generidade." (BARROCO, 2010, p. 66).

O pensamento, decorrente das ultrageneralizações da vida cotidiana, tende a alienação; esta é gerada pela assimilação imediata e acrítica dos juízos valorativos que determinam o comportamento dos indivíduos, reproduzindo-os no nível do senso comum, servindo como orientador das suas ações. Como mencionamos anteriormente, para Lukács, o cotidiano é o espaço propício para a disseminação de ideologias, uma vez que, a partir dos costumes, observação e experiência, o sujeito reproduz a realidade em sua imediaticidade, como "imagem ideal e sentimental" da consciência, que se torna objetiva, em virtude das representações fenomênicas terem correspondência imediata com o modo de vida dos sujeitos e que autoconfirmam a sua individualidade e o contexto sociocultural que se inserem.

Para tornarem-se seres éticos, os sujeitos precisam sair da singularidade, construindo uma individualidade consciente com o humano-genérico "[...] o indivíduo pode sair de sua singularidade através da moral, elevando-se a motivações humano-genéricas". (BARROCO, 2010 , p. 80). Quando o indivíduo se coloca na busca da ultrapassagem das barreiras fenomênicas, perquirindo a convergência entre a singularidade individual e a totalidade social, passa a dispor de mediações que tornam possíveis suspensões/afastamentos da cotidianidade e viabilizam as objetivações éticas.

\footnotetext{
4 Cabe lembrar que a própria construção da ontologia do ser social para Lukács, serviria como a constituição dos fundamentos necessários para a elaboração da ética da teoria social crítica, que permaneceu no campo dos desejos do autor, que faleceu antes de concluir esta empreitada.
} 
A construção da subjetividade, permite que o indivíduo se aproprie das "atividades teóricas", aproximando-se das objetivações humano-genéricas. Este enriquecimento da consciência e sua forma de se apropriar do "mundo" exterior, reflete um processo de intervenção prática na realidade, que pode se "elevar à dimensão de práxis" como atividade prática recriadora e transformadora e vinculá-la aos projetos de classes.

O pensamento não surge necessariamente ideológico, só se torna ideologia, quando adquire uma funcionalidade e legitimação no âmbito das lutas de classes, sendo respaldado por uma maioria. Assim, originam-se de elaborações teóricas e se transformam em instrumentos de luta social, como conjunto de ideias e valores, como forma de enfrentar os conflitos e antagonismo que perpassam a realidade sócio-histórica: "Isto porque a luta social não visa apenas a transformação da sociedade; pode objetivar também a sua manutenção e legitimação" (BARROCO, 2010, p. 162). Apropriando-se da concepção lukacsiana de ideologia 5 , a autora ressalta a sua dupla função na luta de classes: tanto de ocultamento da realidade e conservação/manutenção do status quo que reproduz formas de reificação, limitando à singularidade ao individualismo, como também, possibilita a universalização dos valores éticos (BARROCO, 2010, p. 163).

Portanto, as possibilidades trazidas pela reflexão teórica, não tem por resultante que pela via analítica se transforma a realidade - isto só é possível, no âmbito da prática social, devidamente preenchida de mediações sobre suas possibilidades reais-concretas - mas a apropriação enriquecida da realidade, contribui com a superação das alienações, da repetição acrítica de normas e condutas morais, que reafirmam posturas de conservação da realidade aparente. $A$ atitude política frente a realidade permite, traçar estratégias de enfrentamento e

5 Segundo Lukács (2013) o âmbito da superestrutura ideológica compõe as atividades não econômicas (como a esfera do direito, a política, a religião e as formas puras da ideologia: a filosofia e a arte), onde os pores teleológicos estão voltados mais especificamente para viabilizarem uma mudança na consciência e no comportamento de outros sujeitos. Dito isto, o autor chama atenção para o surgimento e a disseminação de ideologias que só é possível em uma sociedade de classes, pois, não é a expressão de um pensamento singular, mas de um pensamento coletivo que se tornou necessário para a manutenção do status quo. Assim define: "A ideologia é sobretudo a forma de elaboração ideal da realidade que serve para tornar a práxis social humana consciente e capaz de agir. [...] a ideologia é um meio da luta social, que caracteriza toda sociedade". (LUKÁCS, 2013, p. 465). Lukács reforça que a ideologia não é o mesmo que "falsa-consciência", só é possível entender o que é ideologia considerando a sua atuação e função social: "[...] a ideologia só pode se tornar um poder, uma força no quadro do ser social, quando o seu ser-propriamente-assim convergir com as exigências essenciais do desenvolvimento da essência." (LUKÁCS, 2013, p. 481). Portanto, a ideologia parte da necessidade de resolver os conflitos presentes no próprio desenvolvimento histórico-social, de responder as questões postas, sendo, portanto, eminentemente direcionada para a práxis: está direcionada para uma realidade a ser modificada. 0 conteúdo ideológico - que precisa ser transformado em veículo teórico ou prático e disseminado - objetiva enfrentar os conflitos sociais suscitados conforme o desenvolvimento da totalidade. 
desmistificação das contradições legitimadas e contribui com a projeção de novas formas e possibilidades de um vir a ser do cotidiano.

Além de um conjunto normativo de regras de conduta profissional, os valores contidos neste código identificam uma clara perspectiva de classe, como norte orientador de princípios humano-genéricos. Assim, é um instrumento técnico, ídeo-teórico e político.

O CE se orienta por referências teóricas, filosóficas, por valores e finalidades que fazem de um projeto profissional historicamente construído, cujo adensamento político depende do avanço de sua base de sustentação ídeo-política: a organização da classe trabalhadora e dos movimentos contra-hegemônicos da sociedade. Sem essa base concreta e sua consciência teórica, a ética profissional torna-se abstrata (BARROCO; TERRA, 2012, p. 108).

Na construção teórica de Barroco, que trata diretamente da dimensão ético-política, foi possível a identificação do significado e função social da profissão, bem como dos pressupostos teóricos e ideológicos que lhe servem de esteio, com ênfase para a sua dimensão política. A vinculação da teoria à prática social dos sujeitos (expressa nos pressupostos ontológicos que orientam o código de ética de 1993 e o atual projeto ético-político profissional), com a perspectiva de classe, na luta pelos valores emancipatórios humanogenéricos - em contraponto com os códigos anteriores ao processo de renovação configuram elementos importantes da sua elaboração, que remetem a mediação teóricoprática. Também é possível observar que o código de ética de 1993 é a expressão mais forte do pensamento de Lukács na profissão, apropriando-se de muitas de suas categorias centrais.

Importa considerar que para uma parcela da categoria profissional este é um dos componentes do projeto ético-político de difícil materialização, tratando os ideais expressos no CEP como irrealizáveis, como conceitos abstraídos de materialidade histórica. No contexto da inserção profissional - considerando as requisições institucionais imediatas, a focalização das demandas, somadas a complexificação da "questão social" - há a dificuldade de relacionar estes valores com o cotidiano, tendo por resultante o reforço da dicotomização entre teoria e prática. Estes discursos além de restringirem os valores éticos, reproduzem acriticamente as ideologias conservadoras, bem como, contribuem com a desvalorização do pensamento de Lukács.

A dimensão política da profissão, encontra nas obras analisadas, uma relevância notória. É esta postura política que leva os profissionais a questionarem a realidade aparente, a buscar o fortalecimento dos mecanismos de articulação coletiva da categoria e a construir 
estratégias, através dos recursos teóricos, que viabilizem a ultrapassagem dos fenômenos reificadores, na identificação das ideologias das classes sociais em disputa e das alienações que repercutem na imediaticidade do cotidiano, conformando uma clara alusão à mediação teórico-prática.

Analisando a presença de Lukács no debate do Serviço Social, Sousa (2010) identificou que havia na produção intelectual do Serviço Social poucas elaborações que tinham por subsídio o pensamento do autor, realidade esta que, a nosso ver, permanece na atualidade. Como buscamos demostrar, a influência de Lukács contribuiu com a análise dos fundamentos do Serviço Social, problematizando questões até então inéditas ao acervo categorial da profissão. Para além da contribuição teórico-metodológica, a apropriação de Lukács no código de ética profissional, revela a natureza política do seu pensamento, na busca de alternativas para a construção de uma práxis revolucionária e emancipatória.

Diante do que expusemos até aqui, concordamos com Sousa (2010), na acepção segundo a qual a essência ontológica do pensamento lukacsiano é incompatível com a ambiência social e acadêmica contemporâneas, marcadas pela reposição das análises fragmentárias e imediatistas da realidade, resultantes das investidas neoconservadoras sobre o processo de formação profissional e produção do conhecimento. Tendo em vista os desafios que se processam no atual tempo histórico para o Serviço Social, pensamos que o resgate do pensamento de Lukács, se torna fundamental para entender a essência das contradições que atravessam a profissão.

\section{Considerações Finais}

A partir dos elementos trabalhados é possível extrair algumas sínteses provisórias, que podem ser lapidadas e colocadas como novos problemas de pesquisa. De um ponto de vista geral, destaca-se a relevância da tradição marxista para a problematização sobre o significado social do Serviço Social no Brasil. Situar essa profissão no contexto da reprodução das relações sociais, entendidas como resultantes de uma complexa rede de mediações advindas das lutas de classes, permite a problematização dialética das determinações históricas, objetivas, que estabelecem seu arco de possibilidades. Isso significa o afastamento de leituras maniqueístas, moralistas ou conservadoras.

Significa, além disso, uma visão matizada e saturada sobre a categoria de luta de classes, em seu conteúdo dialético, dinâmico, histórico, que confere conteúdo às contradições 
totalizantes da sociedade burguesa, mas também significado concreto para os dilemas das subjetividades mais singulares.

Essas características, por si só, já demarcam um conteúdo específico para as reflexões sobre as relações entre a profissão e a sociedade brasileira. Porém, pelo que foi levantado a partir da revisão bibliográfica realizada, a contribuição da perspectiva ontológica representa um adensamento substantivo no interior da influência marxiana na produção intelectual do Serviço Social brasileiro.

Entre outras razões, por enriquecer a crítica da economia política e sua já clássica contribuição acerca das formas e conteúdos da reprodução do capital e da luta de classes, com uma concepção mais abrangente sobre a própria constituição do ser social como um complexo de complexos, fundado pela categoria ontológica do trabalho, mas de maneira nenhuma limitado a ele. Aliás, o significado da ontologia do ser social reside, precisamente, em estabelecer a forma e o conteúdo do desenvolvimento das categorias que compõem o ser social, em suas relações dialéticas e de relativa autonomia.

Acrescentamos que a categoria do cotidiano tem destaque nas obras abordadas, com implicações sobre a relação entre teoria e prática, especialmente na obra de Netto. A categoria ontológica do cotidiano, nesse contexto, é fundamental para o Serviço Social, pois permite à profissão entender que sua intervenção, mesmo sendo fundada nessa dimensão, pode desencadear processos de superação da imediaticidade, buscando mediações e determinações históricas que conferem concretude e objetividade à prática e a produção de conhecimento. Isso porque a reflexão teórica advém da práxis concreta, resulta das reflexões sobre as questões suscitadas no processo de intervenção sobre a realidade.

As categorias da razão, dos valores, da alienação e da subjetividade comparecem nas reflexões de Guerra e Barroco. Fundadas a partir dos desdobramentos da categoria trabalho, como dimensões ontológicas do ser social, todas essas categorias estão atreladas teoricamente ao complexo da reprodução social, entendida no contexto da perspectiva ontológica, como síntese das tendências histórico-universais e das singularidades dos atos individuais. A reprodução social articula, portanto, totalidade e indivíduo, expressando as categorias do ser social no cotidiano. Os autores, portanto, recuperam do Lukács da Ontologia do ser social o conteúdo das suas reflexões.

Ante o exposto, podemos considerar que a hipótese de trabalho revelou consistência a partir da pesquisa bibliográfica apresentada. No interior da tradição marxista, a perspectiva 
ontológica de Lukács oferece problematizações de natureza teórica e de método, que consistem em adensamentos específicos e particulares à reflexão sobre o significado social do Serviço Social no contexto da reprodução das relações sociais, incluindo a concepção sobre a relação entre teoria e prática.

\section{Referências}

BARROCO, Maria Lúcia Silva. Ética: fundamentos sócio-históricos. 3. ed. São Paulo: Cortez, 2010.

BARROCO, Maria Lúcia Silva; TERRA, Sylvia Helena. Código de ética do/a assistente social comentado. São Paulo: Cortez, 2012.

GUERRA, Yolanda. A força histórico-ontológica e crítico-analítica dos fundamentos. Revista Praia Vermelha, Rio de Janeiro, v. 1, n. 1, 2004.

GUERRA, Yolanda. A instrumentalidade do Serviço Social. 7. ed. São Paulo: Cortez, 2009.

IAMAMOTO, Marilda Villela. Serviço Social em tempo de capital fetiche: capital financeiro, trabalho e questão social. 8. ed. São Paulo: Cortez, 2014.

LUKÁCS, György. Para uma ontologia do ser social II. Tradução de Nelo Shneider, Ivo Tonnet e Ronaldo Vielmi Fortes. São Paulo: Boitempo, 2013.

NETTO, José Paulo. Capitalismo Monopolista e Serviço Social, 8a ed. São Paulo: Cortez, 2011.

SOUSA, Adrianyce Angélica Silva de. Lukács no debate do Serviço Social brasileiro. 2010. Tese (Doutorado) - Universidade Federal do Rio de Janeiro, Rio de Janeiro, 2010.

WELLEN, Henrique. Marxismo e Serviço Social: mediações e contradições entre teoria e prática. Revista Argumentum, Vitória, v. 10, n. 2, p. 122-134, 2018. 